\title{
A CONTRIBUIÇÃO DA ANÁFORA ENCAPSULADORA PARA A ORGANIZAÇÃO DA INFORMAÇÃO EM DISSERTAÇÕES
}

\author{
Maria Audirene de Souza Cordeiro* \\ Maria Eulália Sobral Toscano**
}

\begin{abstract}
Resumo: Este trabalho apresenta o resultado de um estudo sobre a contribuição da anáfora encapsuladora para a organização da informação em dissertações. Para essa pesquisa foram utilizados 60 textos produzidos por alunos do $3^{\circ}$ ano do Ensino Médio do Colégio Dom Amando, localizado em Santarém, no estado do Pará. A base teórica assenta-se nos estudos de Koch (1997, 2001, 2004, 2005), Marcuschi (2001, 2002), Cavalcante (2001, 2003), Souza (2003), Mondada (2003), Apothéloz (2003), Apothéloz e Chanet (2003), Milner (2003), Conte (2003) e Francis (2003). Os resultados mostram que anáfora encapsuladora se trata realmente de um mecanismo fundamental para a organização das seqüências argumentativas, porque, ao sumarizar porções textuais antecedentes, esse tipo particular de anáfora permite ao produtor do texto: a) trabalhar com diferentes argumentos $e$ relacioná-los entre si sem repetir seqüências já mencionadas; b) conduzir a linha argumentativa de tal forma que o leitor seja convencido da validade do juízo de valor defendido no texto; e c) sinalizar mudanças na seqüência argumentativa, indicando que o autor do texto está passando de um estágio argumentativo para outro. Além disso, dependendo do nome escolhido para compor a anáfora encapsuladora, pode-se perceber como o produtor avalia e quer que o leitor interprete as seqüências anteriores às quais a anáfora encapsuladora faz remissão.
\end{abstract}

Palavras-chave: referenciação - anáfora encapsuladora dissertação

\footnotetext{
* Mestra em Lingüística pela UFPA, professora do Colégio Dom Amando Santarém (PA) e da Secretaria Estadual de Educação do Estado do Pará.

** Doutora em Lingüística pela USP, professora da Universidade Federal do Pará.
} 


\section{Introdução}

Não é nenhuma novidade para professores e/ou pesquisadores da área de linguagem o fato de os alunos do Ensino Médio demonstrarem dificuldade para garantir a integração semântica entre as seqüências constitutivas do gênero dissertação.

Uma das explicações para isso está diretamente relacionada à ausência de um tratamento mais articulado do texto em que se considerem as estratégias de construção textual e de progressão e manutenção temática, como a anáfora encapsuladora, por exemplo.

O que se vê, na maioria das salas de aula, é a prática de uma escrita mecânica que se limita a exercitar, de forma isolada, tópicos como a identificação do sujeito e do predicado nas orações, classificação de períodos, diferenciação entre adjunto e complemento nominais, e, sobretudo, o uso "correto" da colocação pronominal, da regência e da concordância verbal; muitas vezes tendo como escopo da análise a sentença.

Esses conteúdos precisam ser considerados em função dos textos de que são parte constitutiva e não por meio de regras e orações/sentenças descontextualizadas.

$\mathrm{Na}$ tentativa de mostrar a produtividade de se considerar nas aulas de língua portuguesa as estratégias de referenciação, é que neste trabalho analisamos a contribuição da anáfora encapsuladora para organização da informação em dissertações.

\section{Referenciação}

A referenciação constitui-se como uma atividade discursiva em que

(...) o sujeito, por ocasião da interação verbal, opera sobre o material lingüístico que tem à sua disposição, operando escolhas significativas para representar estados de coisas, com vistas à concretização de sua proposta de sentido. (KOCH, 2004, p. 61)

Essas escolhas dizem respeito, segundo Koch (2004), ao uso das expressões nominais ou referenciais que desempenham diferentes funções cognitivo-discursivas no processo de construção textual.

Tais expressões podem ser divididas em dois blocos:

(i) as que introduzem novos referentes, sem promoverem nenhum tipo de continuidade referencial; e (ii) as que realizam a continuidade referencial de objetos presentes no universo discursivo, ou porque foram explicitamente evocados ou porque são dali inferíveis. (CAVALCANTE, 2003, p. 106) 


\subsection{Construção da Referenciação}

Segundo Koch (2004, p. 62), para a construção da referenciação "estão envolvidas, como operações básicas, as seguintes estratégias: construção/ativação; reconstrução/reativação e desfocalização/desativação". Assim sendo, o produtor de um texto, no momento da efetivação do discurso, pode recorrer a diferentes processos de construção dos objetos de discurso.

A ativação de um objeto de discurso, conforme Koch (2004), acontece quando

um "objeto" textual até então não mencionado é introduzido, passando a preencher um nódulo ("endereço" cognitivo, locação) na rede conceitual do modelo de mundo textual: a expressão lingüística que o representa é posta em foco na memória de trabalho, de tal forma que esse "objeto" fica saliente no modelo. $(\mathrm{KOCH}, 2004$, p. $62)$.

É, portanto, por meio da ativação de um objeto textual que o produtor do texto põe uma expressão lingüística em foco, a partir da qual passa a construir uma rede semântica que lhe permite não perder de vista informações conceituais referentes ao tema sobre o qual pretende discorrer. $\mathrm{O}$ exemplo (1) mostra isso muito bem.

(1)

Segunda-feira nublada, Frei Betto liga e sugere que a entrevista seja num restaurante próximo ao escritório provisório do projeto Fome Zero. É na Vila Mariana, em São Paulo, onde era o comitê da campanha do presidente Luiz Inácio Lula da Silva. "Prazeres da Carne, é uma churrascaria que fica ali perto", diz. O riso é quase inevitável. Mas o nome provocativo da casa sugerida pelo frade dominicano passa despercebido por ele. O frei em questão é diferente. Carlos Alberto Libânio Christo, 57 anos, é um homem que não se prende ao varejo da vida. (Revista IstoÉ Gente, 6/1/2003, p. 9).

Assim, o produtor do texto passa a selecionar e organizar informações em torno desse objeto de discurso (Frei Betto) que vai sendo construído, durante o processo de constituição dos demais segmentos textuais. Para tanto, o produtor do texto vale-se dos sintagmas nominais: "frade dominicano", "o frei em questão", "Carlos Alberto Libânio" e "um homem que não se prende ao varejo da vida".

Durante esse processo de construção/reativação, pode acontecer também a desfocalização/desativação do objeto de discurso. Trata-se da estratégia que ocorre 
quando um novo objeto-de-discurso é introduzido, passando a ocupar a posição focal. O objeto retirado de foco, contudo, permanece em estado de ativação parcial (stand by), podendo voltar à posição focal a qualquer momento; ou seja, ele continua na memória dos interlocutores. (KOCH, 2004, p. 62).

A reconstrução/reativação é operada, de acordo com Koch (2004, p. 62), "quando um nódulo já presente na memória discursiva é reintroduzido na memória operacional, por meio de uma forma referencial, de modo que o objeto-de-discurso permanece saliente (o nódulo continua em foco)".

No exemplo (1), além de se poder verificar a estratégia de ativação de um objeto de discurso, no caso Frei Betto, podem se constatar as estratégias de desfocalização ou desativação temporária e a reativação desse objeto de discurso. Quando um novo objeto de discurso "restaurante" é ativado, há a desfocalização de Frei Betto. A partir dessa inserção, as seqüências textuais seguintes passam a ter 'restaurante' como objeto de predicação, sem que isso determine a desativação total de 'Frei Betto', que, por continuar em stand-by, é mantido e reativado na memória discursiva do leitor pelo produtor do texto, a partir das expressões nominais 'frade dominicano', 'O frei', 'Carlos Alberto Libâneo Christo', e 'homem que não se prende ao varejo da vida'.

A progressão referencial sempre foi uma preocupação dos estudos sobre textualidade, porém, nos últimos anos, a análise desse mecanismo ganhou ainda mais relevância, uma vez que os estudos deixaram de limitar-se à compreensão dos nexos interfrásicos e passaram a considerar as dimensões pragmático-discursivas que envolvem a construção das redes referenciais em um texto.

A perspectiva atual, explica Cavalcante,

(...) concebe o referente como uma representação 'fabricada' do que existe na realidade, não como o objeto mundano em si mesmo, e supõe uma ação mútua entre língua e práticas sociais, em que, numa trajetória circular e ininterrupta, 'a práxis cria a estereotipia de que depende a língua e esta, por sua vez, materializa e reitera a práxis'. (CAVALCANTE, 2003, p. 105).

Essa nova concepção do referente alterou a compreensão do que se entendia por expressões referenciais, ou seja, essas expressões deixaram de ser consideradas como a

(...) simples representação extensional de referentes do mundo extramental, mas sim como aquilo que designamos, representamos, sugerimos quando usamos um termo ou criamos uma situação discursiva referencial com essa finalidade: as entidades 
designadas são vistas como objetos-de-discurso e não como objetos-do-mundo. (KOCH, 2004, p. 57).

Assim sendo, passam a ser consideradas expressões referenciais "todas as formas de designação de referentes" (CAVALCANTE, 2003, p. 106). Essas formas exercem duas funções basicamente

(...) introduzem novos referentes no 'universo do discurso' (Lyons, 1977) sem promoverem nenhum tipo de continuidade referencial; e realizam a continuidade referencial de objetos presentes no universo do discurso ou porque foram explicitamente evocados ou porque são dali inferíveis. (CAVALCANTE, 2003, p. 106).

É graças a esses mecanismos que o produtor atualiza os conhecimentos do interlocutor, por meio de informações novas; indica que está passando a um outro estágio argumentativo através do fechamento do tópico anterior ou de seu encapsulamento; e orienta argumentativamente o leitor.

Como se trata de um campo vasto, analisamos, neste artigo, como já frisamos antes, apenas uma dessas estratégias: a anáfora encapsuladora que, segundo Conte (2003, p. 178), "é um recurso coesivo pelo qual um sintagma nominal funciona como uma paráfrase resumitiva de uma porção precedente do texto".

Entendemos que

(...) para haver continuidade não é obrigatório, com efeito, que exista sempre uma retomada total ou parcial de um mesmo referente como nas anáforas diretas. Pode ser que a ligação se estabeleça entre uma âncora e outro elemento cotextual introduzido pela primeira vez no texto, como nas anáforas indiretas e encapsuladoras. (CAVALCANTE, 2003, p. 108).

\section{Anáfora}

Neste trabalho, consideramos anáfora no sentido amplo, proposto por Koch (1999) e por Marcuschi (2000), como a relação entre dois segmentos textuais - o que, segundo Jubran (2003, p. 95), "engloba e ultrapassa a definição tradicional de anáfora como estratégia de retomada, geralmente pronominal, de um item lexical colocado anteriormente no texto, com correferencialidade entre os elementos em relação". 
Assim sendo, as relações anafóricas entre os antecedentes podem "ser explícitas quando o antecedente é identificável no texto ou implícitas quando o antecedente é inferido no discurso." (ROCHA, 2003, p. 124).

Ao tratar do antecedente, Apothéloz (2003) faz as seguintes considerações:

(...) o que precede tem duas consequiências importantes para a concepção geral do que é uma forma de retomada: em primeiro lugar (...) as formas de retomada são, antes e acima de tudo, expressões referenciais no sentido mais geral do termo. E, em segundo lugar, o que se chama comumente de antecedente (...) não é, na realidade, um elemento de modo algum indispensável ao funcionamento das formas de retomada. (APOTHÉLOZ, 2003, p. 57).

A seguir, tem-se um quadro demonstrativo da função de cada um dos tipos de anáfora sem retomada, transcrito de acordo com a classificação tipológico-funcional proposta por Cavalcante (2003, p. 113-116).

\begin{tabular}{|l|l|}
\hline \multicolumn{2}{|l|}{ Anáfora sem retomada } \\
\hline Tipo & Função \\
\hline $\begin{array}{l}\text { Anáfora indireta com categorização de um novo } \\
\text { referente }\end{array}$ & $\begin{array}{l}\text { Introduz um referente novo que mantenha uma relação de parte } \\
\text { pelo todo facilmente associável ao seu todo. }\end{array}$ \\
\hline Anáfora indireta com recategorização lexical implícita & Modifica o referente por meio de silepse. \\
\hline Anáfora indireta com recategorização lexical & Reconstrói o referente por meronímia. \\
\hline Anáfora encapsuladora & $\begin{array}{l}\text { Resume proposições do discurso, empacotando-as numa } \\
\text { expressão referencial. }\end{array}$ \\
\hline Anáfora encapsuladora com dêitico & $\begin{array}{l}\text { Resume as proposições do discurso por meio de um dêitico, } \\
\text { geralmente um pronome demonstrativo, ou por meio de uma } \\
\text { expressão referencial encapsuladora precedida de um dêitico. }\end{array}$ \\
\hline
\end{tabular}

Quadro 1 - Tipos de anáfora sem retomada e suas respectivas funções

Conforme o quadro 1, o antecedente não é condição obrigatória para a existência da anáfora, mas sim a remissão a objetos-de-discurso mencionados ou inferíveis do cotexto que lhe serve de fonte. 
Concebemos, portanto, a anáfora como

(...) expressões definidas [e expressões indefinidas e pronominais] que se acham na dependência interpretativa em relação a determinadas expressões nominais [ou informações constantes] da estrutura textual precedente [ou subsequente] e que têm duas funções referenciais textuais: a introdução de novos referentes (até aí não nomeados explicitamente) e a continuação da relação referencial global. (MARCUSCHI, 2005, p. 59).

\subsection{Anáfora Encapsuladora}

Para Conte (2003, p.178), a anáfora encapsuladora é um "recurso coesivo pelo qual um sintagma nominal funciona como uma paráfrase resumitiva de uma porção precedente do texto".

Esse caráter cognitivo-discursivo faz da anáfora encapsuladora uma estratégia importantíssima para organização da informação em dissertações, uma vez que ela permite ao produtor não só construir uma rede de relações referenciais sobre o tema em questão, mas sumarizar uma porção discursiva precedente, interpretando-a. Por conta disso, o encapsulamento, além de possibilitar ao produtor organizar de forma mais coerente o texto, indica ao leitor como interpretar o que está sendo dito, e acompanhar o percurso argumentativo proposto pelo produtor.

\section{Resultados}

Os resultados que ora apresentamos dizem respeito à verificação do uso da anáfora encapsuladora na organização da informação em 60 dissertações de quatro turmas de $3^{\circ}$ ano do Ensino Médio, do Colégio Dom Amando, localizado no município de Santarém, no estado do Pará.

O tema proposto para a produção dos textos foi tatuagem. Antes de escrever, os alunos leram vários textos sobre o tema, sugeridos pela professora, e expuseram os resultados de uma pesquisa realizada individualmente sobre o assunto. Como cada turma é composta em média por 35 alunos, foram escolhidos 15 textos de cada uma das turmas envolvidas neste estudo.

O objetivo principal da análise era responder aos seguintes questionamentos: a) nos textos em que a anáfora encapsuladora é usada adequadamente, é possível compreender 
como o produtor do texto constrói a argumentação, pois há integração semântica entre as seqüências textuais; b) nos casos em que não há encapsulamento adequado, a compreensão do processo argumentativo fica comprometida; e c) o encapsulamento é uma das estratégias de referenciação mais produtiva para garantir a organização da informação em dissertações.

Nas seções subseqüentes, descrevemos a distribuição da anáfora encapsuladora nos textos analisados, explicamos os problemas que o uso indevido desse tipo de encapsulamento pode causar e o reflexo negativo do não encapsulamento na organização textual, e, finalmente, demonstramos a contribuição da anáfora encapsuladora para a organização da informação em dissertações.

\subsection{Contextos de inserção da anáfora encapsuladora}

Nos 15 textos, as anáforas encapsuladoras foram usadas em 1) início do primeiro período do parágrafo; 2) início do segundo período do parágrafo; 3) início de orações no interior de período; e 4) em final de orações que encerram períodos.

A fim de saber se e como o uso das anáforas encapsuladoras (AE) nesses diferentes espaços textuais poderia interferir na funcionalidade desse mecanismo, analisei cada um deles.

\subsubsection{Início do primeiro período do parágrafo ${ }^{1}$}

No início do primeiro período do parágrafo, a anáfora encapsuladora demonstrou ser um recurso importantíssimo para a organização do processo argumentativo. Isso porque, na passagem de um parágrafo para o outro, o produtor se valeu desse tipo de encapsulamento para fazer não apenas uma remissão ao que foi afirmado anteriormente, mas também para indicar a localização exata da seqüência antecedente que estava sendo encapsulada, garantir a integração semântica entre essas seqüências e indicar como a porção textual anterior deveria ser interpretada pelo leitor.

Por meio desse procedimento, o produtor do texto ajudou o leitor a compreender mais facilmente o processo argumentativo e, conseqüentemente, conduziu-o a aceitar o ponto de vista proposto.

Os exemplos (4) e (5) comprovam essas diferentes funçionalidades, pois neles as anáforas encapsuladoras fazem remissão ao processo argumentativo do texto como um todo, uma vez que remetem ao ponto de vista apresentado no início do texto e, ao mesmo tempo, introduzem o argumento considerado mais consistente para comprová-lo.

\footnotetext{
${ }^{1}$ Apesar de haver nomenclaturas mais modernas para denominar porções textuais como às que aqui me refiro, optei pela denominação apresentada pela Gramática Tradicional, por ser mais conhecida e usual.
} 
Assim, esse tipo de encapsulamento, quando usado no início do primeiro período do parágrafo, permite ao produtor não só organizar o processo argumentativo, mas ajuda-o a induzir o leitor a aceitar o ponto de vista proposto, pois atua como um ponto nodal do texto, remetendo a uma etapa argumentativa anterior, fechando-a e iniciando outra. O exemplo (4) e a análise que o segue comprovam claramente essa estratégia de textualização.

(4)

\section{Demonstração de personalidade}

A tatuagem não é mas como se pensava antes, algo que identificava os "marginais da sociedade". Hoje pessoas de todas as idades e estilos fazem, uma e acabam fazendo a segunda, e muitos não passam por ai. Porém muitos pais ainda têem a mentalidade limitada e preconceituosa e proíbem seus filhos adolescente de fazerem. Isso é uma repressão, ir contra um tipo de arte. Porque ser contra tatuagens?

Na maioria das vezes, quem faz uma "tatoo", faz um desenho que tenha haver consigo, que demonstre como ela é, expõe na pele sua personalidade, e muitas vezes é para todos verem. Se um jovem tem consciência, e quer fazer, ele não deve ser reprimido pelos pais, os pais têem que compreendem o motivo e apoiar. Caso o adolescente se arrependa no futuro, a tatuagem já pode ser retirada, com um método a lazer.

A tatuagem é uma arte, se as pessoas prestarem mais atenção, é uma arte milenar, porque os índios pintavam e marcavam seus corpos, mas guerras e suas tradições. Os marroquinos têem o costume de fazerem pinturas nos corpos das noivas. $\mathrm{O}$ ato de fazer uma pintura, marcar algo em si, acontece a muito tempo.

Outro fato importante, é que os lugares que fazem as tatuagens hoje em dia, são cada vez mais higiênicas, basta pegar referencias de bons locais. Os materiais são esterelizadas, as salas são limpas, tudo descartável. Os profissionais que fazem, são cada vez mais preparados, fazem vários cursos de técnicas e também são bastante responsáveis.

A tatuagem não é mas uma forma de identificar os "excluídos da sociedade" como era no passado e sim demonstrar as pessoas que não ligam para o preconceito. Serve como um cartão postal, olha para o desenho e pode ter uma idéia de como a pessoa é. E se adolescente quer fazer, o pai deve apoiá-lo, dando conselhos também. (T4/L1-27).

No exemplo (4), o objetivo do autor do texto é provar que "A tatuagem não é mas como se pensava antes, algo que identificava os "marginais da sociedade". Para tanto, afirma: "Hoje pessoas de todas as idades e estilos fazem uma, e acabam fazendo a segunda, e muitos não param por ai". Nos períodos seguintes, acusa os pais que são contra a 
tatuagem de serem repressores e de irem contra um tipo de arte e, finaliza essa etapa, a introdução do texto, questionando: Por que ser contra tatuagens?

É justamente para tentar provar que não há motivos para ser contra a tatuagem que o autor apresenta uma série de argumentos favoráveis ao uso da tatuagem: no segundo parágrafo, afirma que os pais não devem proibir os filhos de fazer uma tatuagem, porque ela pode ser facilmente removida; no terceiro, comprova que a tatuagem é uma arte milenar cujos objetivos são nobres; e no quarto parágrafo, último do desenvolvimento e preparatório para conclusão, portanto, um ponto nodal do texto, o autor usa a anáfora encapsuladora outro fato importante para apresentar o último argumento proposto, a saber, o de que fazer uma tatuagem hoje não coloca a saúde de ninguém em risco.

Por meio desse mecanismo sumarizador, o autor do texto marca claramente a enumeração de "fatos importantes" e insere o que seria seu argumento mais contundente para provar que não há motivos para as pessoas serem contra a tatuagem: "os lugares que fazem as tatuagens hoje em dia, são cada vez mais higiênicas, basta pegar referencias de bons locais. Os materiais são esterelizadas, as salas são limpas, tudo descartável. Os profissionais que fazem, são cada vez mais preparados, fazem vários cursos de técnicas e também são bastante responsáveis".

Assim, no parágrafo seguinte, último do texto, depois de ter organizado os argumentos, por meio da anáfora encapsuladora outro fato importante, o produtor inicia a conclusão do processo argumentativo, reafirmando: "A tatuagem não é mas uma forma de identificar os 'excluídos da sociedade' como era no passado e sim demonstrar as pessoas que não ligam para o preconceito. Serve como um cartão postal, olha para o desenho e pode ter uma idéia de como a pessoa é. E se o adolescente quer fazer, o pai deve apoiá-lo, dando conselhos também".

No exemplo (5), esse mesmo procedimento é usado.

(5)

Arrependimento

O homem sempre procura se diferenciar da sociedade que o cerca, e utiliza inúmeras possibilidades para isso. A tatuagem surge como uma forma de o jovem se expressar colocando seus sentimento marcados na pele. Muitos acabam se arrependendo futuramente pelas conseqüências trazidas por ela na vida profissional.

A tatuagem através de décadas sempre foi vista por grande parte da sociedade como sinônimo de violência, nos dias de hoje esse conceito tem mudado bastante mas no mercado de trabalho ainda existe a discriminação contra pessoas que usam piercing, tatuagem, e outras formas radicais de expressão.

Outro arrependimento que a tatuagem pode trazer é quando a pessoa não gosta da arte ou do desenho feito em sua pele ou quando contrai doenças através do 
compartilhamento de equipamentos entre várias pessoas causado pela incompetência de alguns profissionais que trabalham no mundo da tatuagem.

Existem formas de amenizar as conseqüências causada pelo uso de tatuagem . Saber escolher o local do corpo onde o desenho será feito, o tamanho e o que ele representa traz a possibilidade de a pessoa escondê-la por debaixo da roupa ou do cabelo eliminado a visão da mesma.

A tatuagem não desqualifica um trabalhador, mas a verdade é que a discriminação existe e devemos pensar bastante antes de fazer uma tatuagem, pensar nas conseqüências trazidas por ela futuramente e escolher um bom profissional na área da tatuagem, um profissional que entenda do assunto. (T28/L1-30).

Uma rápida leitura do parágrafo inicial, do exemplo (5), já indica que a principal idéia do produtor é mostrar as conseqüências que fazem com que muitos adolescentes se arrependam de fazer tatuagem.

Para tanto, o autor inicia a enumeração de argumentos que possam garantir a comprovação desse ponto de vista: no segundo parágrafo, apresenta o primeiro motivo para o arrependimento, a saber, a discriminação na área profissional, e no terceiro parágrafo, funcionando como argumento mais forte, introduz outros dois motivos de arrependimentos, quais sejam, não gostar do desenho ou contrair doenças. Para inserir esses últimos argumentos, o autor usa a anáfora encapsuladora outro arrependimento, que além de sumarizar o conteúdo do parágrafo anterior, indica uma nova etapa do processo argumentativo e faz remissão ao ponto de vista proposto na introdução.

Além dessas diferentes funções, essa expressão nominal conduz o leitor à conclusão do texto, uma vez que no parágrafo seguinte, o quarto, o autor do texto propõe formas de amenizar as consequiências elencadas anteriormente e no quinto, o da conclusão, finaliza o texto, ratificando o ponto de vista proposto na introdução: "devemos pensar bastante antes de fazer uma tatuagem, pensar nas conseqüências trazidas por ela futuramente (...)".

Fica claro, portanto, que as anáforas encapsuladoras outro fato importante (exemplo 4) e outro arrependimento (exemplo 5) atuam como importantíssimos mecanismos de organização da informação nos textos analisados, porque fazem remissão a argumentos anteriores, introduzem novos argumentos, organizam o processo argumentativo e ajudam o autor do texto a provar o ponto de vista apresentado na introdução do texto.

\subsubsection{Início do segundo período do parágrafo}

No início do segundo período do parágrafo, a maioria das anáforas encapsuladoras não exerce a mesma função que as anáforas encapsuladoras analisadas no início do 
parágrafo, porque não remetem ao processo argumentativo como um todo, a exemplo do que ocorre com as do primeiro grupo.

$\mathrm{O}$ uso delas nesse contexto limita-se a remeter apenas a sequiências textuais bem próximas, funcionando tão somente como paráfrases resumitivas de enumerações antecedentes, sumarizadas por meio de um lexema que indica como os elementos da enumeração devem ser interpretados pelo leitor.

Nos exemplos (6), (7), (8), (9) e (10), esse procedimento fica evidente, uma vez que a indicação de que a sequiência enumerativa antecedente deve ser entendida como um prejuízo para a pessoa tatuada, é garantida pela escolha dos nomes axiológicos problemas, consequiências e esses preconceitos que, respectivamente, ratificam esse sentido negativo.

(6)

Mancha permanente... arrependimento infinito... preconceito da sociedade: esses são os problemas que uma tatuagem feita por amor ou por pura vontade de se desenhar algo em seu corpo pode causar, deixando muitas vezes que o preconceito haja sobre ela. (T33/L1-5).

Corpos marcados...preconceito...arrependimento, essas são algumas conseqüências para as pessoas que resolveram fazer um desenho permanente no corpo, e que não sabiam que isso poderia atrapalhar e muito suas vidas. (T7/ L1-4).

Também como lado negativo uma pessoa por exemplo ao procurar emprego ela é vista com outros olhos pelas pessoas só porque tem uma tatuagem, também uma pessoa formada em direito for fazer um concurso público não poderar fazer o concurso porque tem uma tatuagem, essas são algumas conseqüêencias que a tatuagem trás. (T29/16-20).

(9)

Arrependimento... dor... desemprego: essas são somente algumas das consequiências que a tatuagem pode trazer se não for muito bem pensada antes de ser feita. A cada dia cresce o número de pessoas que aderem a essa mania, muitas vezes influenciadas por artistas, que são sempre celebradas quando aparecem com uma nova. (T18/L1-6).

Além do setor profissional, sofrem como preconceito social pois quando vão a praia, por menor que seja, todos olham para aquela caricatura estampada, parecendo que ela tem alguma doença muito grave. Depois de ter sofrido com 
todos esses preconceitos ainda tem o familiar, que faz com que estas se sintam ainda piores. (T7/L10-14).

Por outro lado, nos exemplos (11), (12), (13) e (14), o autor optou por um nome encapsulador cujo conteúdo não determina que o leitor interprete de modo negativo as seqüências textuais anteriores.

Nesses exemplos, as anáforas encapsuladoras "esses são alguns motivos", "Esses são alguns reflexos", "esse é o retrato da vida" e "os motivos" indicam apenas como as sequiências anteriores devem ser interpretadas, mas não induzem o leitor a avaliá-las de forma negativa, até porque o conteúdo das porções antecedentes não permite que o produtor proponha ao leitor uma inferência com esse aspecto semântico.

Prova de amor...Vaidade...Revolta: esses são alguns motivos que levam uma pessoa a marcar o próprio corpo. Mais passando por cima de todos esses motivos bons ou ruins existe o preconceito. A maior parte das pessoas não confiam em profissionais tatuados, ou dão preferência aquele que não possui tatuagens. (T2/L1-6).

Desenhos perfeitos, corpos riscados, pais frustrados, um enorme preconceito, pessoas satisfeitas e arrependidas...Esses são alguns dos reflexos existentes que ocorrem quando se trata de tatuagem. Esse tema gera muita polêmica, pois, cada país, região, classe etária, etnia possui sua respectiva idéia, e é claro que são opiniões diferentes, então, gera muito a se discutir. Portanto a tatuagem não é nenhuma praga, “doença”, mas (...). (T27/L1-6).

Desentendimento familiar...preconceito...arrependimento: esse é o retrato da vida de alguns jovens que são tatuados. É cada vez mais freqüente na sociedade a quantidade de pessoas desempregadas por causa do preconceito. Isso ocorre pois a sociedade considera pessoas de má fé. (T12/L1-5).

Chamar a atenção...homenagear familiares...se embelezar... Vários são os motivos que levam uma pessoa afazer uma tatuagem. Muitas fazem para demonstrar seu amor pelo companheiro ou pelos filhos, mas geralmente, principalmente entre os jovens, a tatuagem é feita para mostrar rebeldia, pelo menos é o que a sociedade julga. (T19/L1-5). 
Ressalve-se que, no início do segundo período do texto, apesar de o encapsulamento não remeter ao processo argumentativo proposto, ele é importante para organizar a informação nas seqüências argumentativas, porque, ao inserir uma anáfora encapsuladora no segundo período do parágrafo, o produtor do texto inicia sempre um segundo argumento. Isso faz com que uma informação dada ganhe status de informação nova, pois a partir da sumarização do conteúdo temático anterior, o autor do texto pode construir novas predicações sem prejudicar a manutenção e a progressão temática do texto.

\subsubsection{Início de orações no interior de período}

Em início de oração no interior de período, identificado em sequiências específicas dos exemplos (15), (16), (17), (18), (19) e (20), os nomes que compõem as anáforas não recategorizam, com exceção do exemplo (20), de forma negativa os objetos-de-discurso anteriormente introduzidos, como mostram algumas seqüências dos exemplos (6), (7), (8), (9), (21), (22), (23) e (24).

As anáforas encapsuladoras, identificadas em início de orações no interior de períodos, quais sejam, uma das explicações, esse motivo, esse conceito, esse tema, esse ponto, e esse preconceito, usadas nos exemplos (15), (16), (17), (18) e (19) abaixo, configuram-se, na verdade, como hiperônimos precedidos de demonstrativo, pois o autor do texto se vale de um lexema para subsumir uma sucessão de proposições:

\section{(15)}

$\mathrm{Na}$ antiguidade, a tatuagem era associada ao culto aos deuses demoníacos e era praticada durante ritos dedicados por feiticeiros. O sangue que brotava das feridas, levava junto de si os espíritos malignos. Sendo essa uma das explicações da origem da tatuagem. (T40/L7-12).

Quando se vê alguém com tatuagem logo se imagina que ela é malandra, que não leva nada a sério, e por esse motivo a pessoa que tem tatuagem sofre muitos preconceitos, as vezes não conseguindo nem um emprego por esse motivo enquanto que ela só quer mostrar sua insatisfação com algo. (T19/L6-10). 
O homem sempre procura se diferenciar da sociedade que o cerca, e utiliza inúmeras possibilidades para isso. A tatuagem surge como uma forma de o jovem se expressar colocando seus sentimento marcados na pele. Muitos acabam se arrependendo futuramente pelas conseqüências trazidas por ela na vida profissional.

A tatuagem através de décadas sempre foi vista por grande parte da sociedade como sinônimo de violência, nos dias de hoje esse conceito tem mudado bastante mas no mercado de trabalho ainda existe a discriminação contra pessoas que usam piercing, tatuagem, e outras formas radicais de expressão. (T28/L1-12).

Desenhos perfeito, corpos riscados, pais frustrados, um enorme preconceito, pessoas satisfeitas e arrependidas...Esses são alguns dos reflexos existentes que ocorrem quando se trata de tatuagem, esse tema gera muita polêmica, pois, cada país, região, classe etária, etnia possui sua respectiva idéia, e é claro que são opiniões diferentes, então, gera muito a se discutir. (T27/L1-6).

Em relação a moda dos desenhos definitivos no corpo gera um grande preconceito no mercado de trabalho. A tatuagem gera uma má impressão para as pessoas que correm atrás de um emprego, esse ponto tem que ser visto de uma outra forma, mas toda "regra" tem sua exeção, ou seja, depende do tipo de desenho que possui a pessoa, ninguém vai quere uma pessoa com o símbolo do nazismo estampado no braço. (T27/L12-17).

É importante ainda ressaltar o caso do exemplo (20). Ao contrário das demais, essa sequiência traz uma palavra de cunho negativo esse preconceito que determina como o leitor deverá interpretar as porções textuais anteriores. Dentre os dados analisados no contexto formal 3, esse foi o único caso em que uma anáfora encapsuladora iniciadora do segundo período do parágrafo indica que o leitor deverá interpretar a seqüência encapsulada de modo negativo, o que supostamente foi condicionado pelo conteúdo proposto nas porções textuais.

No contexto atual, a sociedade está aceitando mais as coisas que antes eram tabus, como a tatuagem, e em um futuro não muito distante. Esse preconceito contra os tatuados não será mais tão grande. Mas todos que pretendem fazer uma tatuagem devem pensar nas consequiências pois serão marcas para toda a vida. (T19/L24-28). 
Essas análises parecem demonstrar que o uso de um nome axiológico de conteúdo negativo é condicionado pelo conteúdo das seqüências textuais anteriores. Todavia, para se comprovar essa hipótese, é necessário que se investigue o uso de nomes axiológicos na composição de encapsulamentos anafóricos e, ainda, que se verifique o que determina a opção por um hiperônimo antecedido por demonstrativo como um nome encapsulador.

\subsubsection{Final de orações que encerram períodos}

Em final de orações que encerram períodos, identificamos 5 casos de anáfora encapsuladora, conforme atestam os exemplos (21), (22), (23), (24) e (25). Em (21), (22) e (23), as anáforas foram usadas com conteúdo negativo explícito, introduzido depois do nome encapsulador, via qualificativo. Tal interpretação é cuidadosamente facilitada pelo uso do advérbio 'antigamente', no início do parágrafo, e ratificado pelo produtor do texto que acrescenta no sintagma encapsulador o qualificativo tradicional.

\section{(21)}

Antigamente todo mundo que tinha uma tatuagem no corpo era considerado totalmente "bandido", o preconceito diminuiu mas não acabou, pois tem muitas famílias com esse pensamento tradicional. Apesar de nos dias de hoje esse conceito ter mudado o mercado de trabalho ainda discrimina pessoas tatuadas (T12/L17-21).

Por sua vez, nos exemplos (22) e (23), a possibilidade de se interpretar negativamente as seqüências anteriores é assegurada explicitamente pelo uso dos avaliativos besta e absurdo usados na composição do sintagma nominal encapsulador.

Tatuagem é uma coisa tão atual, que não precisava de todo esse preconceito besta, (T10/L16-17).

(...) as pessoas em vez de ficarem prestando atenção nisso deveriam tentar conhecer melhor essas pessoas, talvez assim elas tirassem essas idéias absurdas. (T10/L17-20). 
Já nos exemplos (24) e (25), a interpretação negativa não é tão explícita, pois fica claro que essa possibilidade de interpretação não é determinada especificamente pelo nome encapsulador, mas pelo conteúdo das seqüências anteriores que imprimem valor negativo aos sintagmas encapsuladores.

No exemplo (24), por meio da expressão nominal desse jeito, o autor do texto induz, de modo implícito, o leitor a interpretar a seqüência textual anterior, encapsulada, de modo negativo, porque o nome encapsulador jeito remete ao fato de os jovens usarem a tatuagem 'para aparecer e chamar atenção', encerrando assim uma etapa do processo argumentativo e, logo em seguida, já em outra etapa desse processo, o produtor enfatiza os problemas que uma tatuagem pode causar aos que aderem a essa moda.

Vale ressaltar que isso só é confirmado com leitura dos parágrafos seguintes, uma vez que tanto o terceiro quanto o quarto parágrafos mostram diferentes problemas vivenciados por quem decide optar por fazer uma tatuagem no corpo.

Esse número vem aumento a cada dia, são jovens com hormônios à flor da pele e que fazem de tudo para aparecer, chamar a atenção de alguma forma.

Mas por que logo desse jeito? Será que elas não pensam nas conseqüências que uma tatuagem pode causar? Geralmente, tudo começa pela influência de um amigo e até mesmo de alguns artistas. As pinturas são várias, rostos palavras, animais, entre outros.

Apesar do número de pessoas com essas pinturas ter aumentado, o preconceito ainda persiste, principalmente quando elas vão em busca de um emprego. As empresas não admitem profissionais com essas marcas corporais, pois podem denegrir sua imagens.

A beleza não é para sempre, com o passar do tempo todos envelhecem e ficam com a apele enrugada, e aí bate o arrependimento pois a pintura se torna feia, desbotada como uma mancha. E vem a vontade de retira-la através de cirurgias plásticas ou a laser, porém a pele nunca volta ser a mesma. (T1/L6-22).

No caso específico do exemplo (25), o nome encapsulador termos não traz em si um conteúdo negativo explícito, mas a sequiência que ele encapsula, a saber, "antigamente a tatuagem era vista como algo que só os 'maloqueiros' usavam discriminando todas as pessoas que tinham e não se enquadravam nestes termos", evidencia que a interpretação proposta é negativa. 
Antigamente a tatuagem era vista como algo que só os "maloqueiros" usavam, discriminando todas as pessoas que tinham e não se enquadravam nestes termos. Mas hoje em dia é bastante comum. É claro que ainda existe aquele preconceito, pelos mais velhos, só que hoje já se encontra médicos, advogados, professores que possuem tatuagem. (T43/L 16-21).

Portanto, é preciso ressaltar que nos exemplos (22) e (23), o caráter negativo indicado pelo encapsulamento é bem mais explícito, porque a anáforas encapsuladoras assumem outra configuração: após o nome encapsulador, o autor do texto inseriu os avaliativos besta e absurdas.

Ao fazer uso desses avaliativos, o autor não deixa dúvidas de como o leitor deve interpretar as porções textuais que foram encapsuladas. No caso dos exemplos (24) e (25), como foi demonstrado, a indução à interpretação negativa não é tão explícita, visto que o leitor precisa do conteúdo das seqüências textuais posteriores e anteriores respectivamente para perceber a intenção do produtor do texto.

Para finalizar a análise dos diferentes contextos formais em que a anáfora encapsuladora é usada nos textos que compõem o corpus desta pesquisa, passamos a analisar um tipo de encapsulamento, por hiperônimo sem o demonstrativo, identificado apenas no exemplo (26).

Hoje em dia está bastante mudado o comportamento de pais e filhos, em virtude disso os jovens estão cada vez mais liberais perante a sua escolha de vida. Antigamente, por exemplo, uma pessoa que usava tatuagem era considerada uma pessoa vulgar, que não tinha os princípios básicos da criação, porém hoje podemos ver que a coisa não é bem assim. (T11/L5-10).

Essa anáfora encapsuladora requer uma caracterização mais detalhada, pois como se pode perceber, ao inseri-la, o produtor do texto opera um tipo de globalização específica, sumarizando todas as informações anteriores no objeto-de-discurso a coisa. Por meio desse hiperônimo, o produtor agrupa sob um lexema os vários processos introduzidos anteriormente. $\mathrm{O}$ fato interessante nesse tipo de procedimento é que ele parece inviabilizar o uso do pronome demonstrativo e exigir o uso do artigo definido.

Como no corpus deste trabalho só foi identificado esse caso, não foi possível fazer uma análise mais minuciosa do uso desse tipo específico de encapsulamento anafórico. Isso abre uma nova possibilidade de análise, a saber, verificar se e em que contextos formais o produtor de dissertações recorre ao uso do artigo definido para encapsular seqüências textuais antecedentes. 
Após a análise dos diferentes contextos formais em que a anáfora encapsuladora foi usada, constatamos que, apesar de se tratar de espaços sintáticos específicos, as funções características desse tipo de encapsulamento, quais sejam, de sumarizar, de interpretar, de organizar a seqüência argumentativa e de indicar o início de uma nova etapa argumentativa não foram alteradas.

\subsection{Uso indevido da anáfora encapsuladora}

A escolha lexical do nome que compõe o encapsulamento é fundamental para que a anáfora encapsuladora funcione como um recurso produtivo de organização da informação, pois, quando essa escolha é inadequada, torna-se mais difícil para o leitor recuperar o percurso argumentativo e as informações indicadas pelas sequiências textuais encapsuladas. O exemplo abaixo é uma prova de como uma escolha lexical inadequada pode comprometer a organização da informação em um texto.

Rebeldia...pinturas corporais...arrependimento: são fatos vividos por muitas pessoas que fazem essas pinturas permanentes em seus corpos. Esse número vêm aumentando a cada dia (...). (T1/L 1-4).

Rebeldia...pinturas corporais...arrependimento: são fatos vividos por muitas pessoas que fazem essas pinturas permanentes em seus corpos. Esse número vêm aumentando a cada dia (...). (T1/L 1-4)².

Nos exemplos em foco, temos dois problemas relacionados à anáfora encapsuladora que comprometem a organização da informação no texto; ambos inviabilizados pelo mesmo motivo: escolha inadequada do nome que ajuda a compor o encapsulamento.

A palavra fatos não resume o conteúdo semântico de todos os elementos que formam a seqüência enumerativa, o que impossibilita o encapsulamento da porção textual anterior e prejudica a compreensão do conteúdo proposicional dos enunciados.

Vale ressaltar que não nos é possível saber com precisão a que porção textual anterior à expressão nominal encapsuladora esse número faz remissão. O que acontece,

\footnotetext{
${ }^{2} \mathrm{O}$ fragmento foi repetido por se tratar de duas anáforas encapsuladoras com nomes diferentes.
} 
nesse caso, é que o esforço cognitivo do leitor é maior e o percurso que constrói o sentido do texto torna-se sinuoso.

Portanto, quando o produtor do texto escolhe, para o encapsulamento, um item lexical que não garante a integração semântica de forma clara, ele compromete seriamente a construção do processo persuasivo: 1) dificulta a localização da seqüência antecedente que está sendo encapsulada, 2) não garante a integração semântica entre as seqüências que estão sendo relacionadas, 3) exige do leitor uma capacidade maior de interpretação para que compreenda a relação argumentativa entre as seqüências textuais que compõem o texto, e 4) não indica de que forma a sequiência antecedente deve ser interpretada pelo leitor, como evidenciam os exemplos (27) e (28).

\subsection{Reflexo negativo do não encapsulamento}

Nos textos em que a anáfora encapsuladora não foi usada, não foram identificados problemas graves de integração semântica entre as seqüências. Todavia, o produtor parece ser forçado a recorrer ao pronome isso para fazer retomadas ou remissões, quando em alguns casos o mais indicado seria optar pelo uso da anáfora encapsuladora.

Nos exemplos (29) e (30) abaixo, substituimos o referido pronome por anáforas encapsuladoras para demonstrar como o texto ganha em qualidade argumentativa quando é usado o encapsulamento anafórico.

Quem já não teve vontade de deixar algo marcado no corpo para o resto da vida? Um símbolo, um desenho, uma frase, nome de alguém querido ou o próprio, uma letra ... as variedade são muitas. E é por (isso) essa razão que tanta gente anda se tatuando. (T47/L1-5).

O problema é quando uma pessoa desempregada resolve fazer uma tatuagem a amostra, ai aparece um emprego em uma empresa e não dão por causa da tatuagem. (Isso)Esse tipo de atitude sim acho preconceito pois eles não vão pelas pessoas pelo seu eu, e sim pela sua aparência. ( T50/L23-29).

Após analisar os contextos sintáticos em que as anáforas encapsuladoras foram usadas nos textos do corpus, caracterizar o problema que a escolha inadequada de um nome para compor o encapsulamento pode causar no processo de construção textual e demonstrar 
o reflexo negativo do não encapsulamento anafórico, é preciso explicar como a anáfora encapsuladora contribui para a organização da informação em dissertações.

\subsection{Contribuição da anáfora encapsuladora para a organização da informação}

O produtor do texto, por meio do encapsulamento anafórico, pode não só recategorizar segmentos precedentes e subseqüentes do cotexto, mas também acrescentar modificadores avaliativos, assegurar a integração semântica entre as seqüências e indicar como o leitor deverá interpretá-las.

Essas diferentes funções desempenhadas pelo encapsulamento anafórico possibilitam ao produtor do texto não só organizar as seqüências argumentativas de forma a tornar o processo argumentativo mais claro, mas ajuda-o a conduzir o leitor à (a) interpretação das sequiências textuais de modo que ele aceite os pontos de vista propostos no decorrer do texto.

Assim, pode-se afirmar que as hipóteses apresentadas no início deste trabalho foram comprovadas, uma vez que os exemplos de (4) a (25) mostram que, nos textos em que a anáfora encapsuladora é usada adequadamente, é possível compreender como o produtor do texto constrói a argumentação. Por outro lado, nos casos em que não há encapsulamento adequado, a compreensão do processo argumentativo é comprometida, como atestam os exemplos (27) e (28).

A comprovação dessas duas hipóteses, respectivamente a e b, e a análise dos textos em que não há encapsulamento anafórico ratificam a hipótese c: o encapsulamento é uma das estratégias de referenciação mais produtivas para garantir a organização da informação em dissertações.

Nas dissertações em que essa estratégia foi usada, as seqüencias textuais apresentam um caráter organizacional maior e permitem ao leitor recuperar o percurso argumentativo proposto pelo produtor do texto.

Percebe-se, portanto, conforme demonstram os dados analisados, que a anáfora encapsuladora é uma estratégia muito produtiva na organização da informação em dissertações. Isso porque

1) exerce uma das funções dos pronomes anafóricos, qual seja, a de fazer remissão a porções textuais anteriores, sem antecedente específico, resumindo-as. Isso permite ao produtor do texto trabalhar com diferentes argumentos e relacioná-los entre si sem repetir sequiências já mencionadas;

2) amplia a função anafórica dos pronomes, porque, além de resumir sequências textuais anteriormente citadas, indica como essas porções textuais devem ser interpretadas pelo leitor. Essa característica possibilita ao produtor conduzir a linha argumentativa de tal forma que o leitor seja convencido da validade do juízo de valor defendido no texto; 
3) garante a integração semântica entre as seqüências. Essa terceira função da anáfora encapsuladora ajuda o produtor a manter a logicidade entre as diferentes porções textuais que constituem o texto e marca a posição defendida pelo produtor do texto em relação ao que já foi mencionado. Por meio da escolha lexical do nome, quando axiológico, pode-se perceber como o produtor avalia e quer que o leitor avalie as seqüências anteriores às quais a anáfora encapsuladora faz remissão; e

4) sinaliza mudanças na sequiência argumentativa, indicando que o autor do texto está passando de um estágio argumentativo para outro. Essa função ajuda o produtor a organizar o processo argumentativo em diferentes estágios, e indica ao leitor a mudança e, ao mesmo tempo, o fechamento do argumento anterior por meio de seu encapsulamento em uma forma nominal.

A variedade de funções e características supramencionadas indicam que o funcionamento dessa estratégia de referenciação deveria ser mais claramente explicitado nas aulas de produção de texto, pois, ao usar o encapsulamento anafórico, os alunos poderiam aprender não só a organizar as sequiências textuais, mas a relacionar argumentos e a sumarizá-los, a fim de construir textos em que o processo argumentativo fosse melhor sistematizado.

Percebe-se que a anáfora encapsuladora é realmente um dos recursos mais produtivos para persuadir o leitor da dissertação, pois, dependendo da escolha que se faz do núcleo de um sintagma encapsulador, o produtor não só retoma porções textuais antecedentes, mas integra semanticamente as seqüências argumentativas e indica como o leitor deverá interpretá-las.

Essa estratégia de referenciação, portanto, orienta argumentativamente o texto e ajuda o produtor a atingir seu objetivo maior que é o de persuadir o leitor a aderir ao ponto de vista por ele defendido no texto, neste caso, na dissertação.

\section{Conclusões}

É necessário que os currículos escolares contemplem a referenciação como uma importante estratégia de construção textual, tornando-a conteúdo obrigatório, e que os professores demonstrem aos alunos o funcionamento da anáfora encapsuladora como um mecanismo fundamental para a organização do processo argumentativo em dissertações, visto que, ela, permite ao produtor do texto não só a organizar as seqüências textuais, mas relacionar argumentos e sumarizá-los, a fim de construir textos, cujo percurso argumentativo seja delineado de modo claro.

As constatações a que chegamos nesta pesquisa estão longe de esgotar as inúmeras contribuições que o estudo da anáfora encapsuladora em dissertações pode trazer para o ensino e aprendizagem desse e de outros gêneros textuais, uma vez que é preciso investigar, entre tantas outras questões: a) o que determina a opção por um hiperônimo como um nome encapsulador; b) se a opção por um hiperônimo inviabiliza o uso do determinante e exige o 
uso do artigo definido e em que contextos formais isso ocorre; e c) se o uso de um nome axiológico de conteúdo negativo é condicionado pelo conteúdo das sequiências anteriores.

Vale ressaltar que algumas conclusões sobre o uso do definido demonstrativo nas nomeações já estão sendo apresentadas por alguns estudiosos como Apothéloz e Chanet (2003), mas é necessário que se verifique a implicação dessas construções na organização do processo argumentativo no gênero dissertação.

Mesmo sabendo que muito ainda há que ser investigado sobre o uso da anáfora encapsuladora em textos escritos, esperamos ter contribuído para uma maior visibilidade da importância dessa estratégia para a organização da informação e do processo argumentativo em dissertações.

\title{
Referências Bibliográficas
}

APOTHÉLOZ, D. Papel e funcionamento da anáfora na dinâmica textual. In: CAVALCANTE, M.M.; RODRIGUES, B.B. \& CIULLA, A. (Orgs.). Referenciação. São Paulo: Contexto, 2003. p. 57.

CAVALCANTE, M. M. Expressões referenciais: uma proposta classificatória. In Cadernos de Estudos lingüísticos. São Paulo: Unicamp, 2003, p. 105-116.

CONTE, M.E. Encapsulamento anafórico. In Referenciação. São Paulo: Contexto, 2003, p. 178.

JUBRAN, C.C.A.S. $O$ discurso como objeto-de-discurso em expressões nominais anafóricas. In: Cadernos de Estudos Lingüísticos. São Paulo: Unicamp, 2003, p. 95.

KOCH, I. G. V. Introdução à lingüística: São Paulo: contexto, 2004, p. 57-62.

Revista IstoÉ Gente, 6/1/2003, p. 9.

ROCHA, M. O conhecimento de colocações no processamento de relações anafóricas. In: Cadernos de Estudos Lingüísticos. Campinas, Jul./Dez. 2003, p.124.

\begin{abstract}
This work shows the result of an investigation about the contribuition of encapsulating anaphora for the organization of information in essays. For this research, it was used 60 (sixty) texts produced by students from $3^{\text {rd }}$ (third) grade of High School from Dom Amando School (Estado e Municipio). The theoretical basis is founded on Koch's (1997, 2001, 2004, 2005), Marcuschi's (2001, 2002), Cavalcante's (2001, 2003), Sousa's(2003), Mondada's ( 2003), Apothéloz's (2003), Apothéloz and Chanet's (2003), Milner's (2003), Conte's (2003) and Francis's works (2003). The results point out that the encapsulating anaphora is really a fundamental mechanism for the organization of argumentative sequences, because in summarizing preceding textual portions, this particular kind of
\end{abstract}


anaphora allows the text producer to: a) work with different arguments and relate them to each other without repeating sequences that have been already mentioned; b) conduct the argumentative line in order that the reader is convinced of the points of view effectively defended in text and c) show changes in the argumentative sequence, indicating that the author's text is getting through from an argumentative point to another one. Besides that, depending on the chosen noun to compose the encapsulating anaphora, we can realize how the producer evaluates and wants the reader to interpret preceding sequences to which the encapsulating anaphora refers.

Keywords: referenciation - encapsulating anaphora - essay 